УДК [330.341.1+ 339.972]

\title{
РАСПРОСТРАНЕНИЕ ТЕХНОЛОГИЙ И ПРЕОДОЛЕНИЕ ТЕХНОЛОГИЧЕСКОГО РАЗРЫВА
}

\author{
А.Ш. МАРГАРЯН \\ канд. экон. наук, доцент, декан факультета регулирования экономики \\ и международных экономических отношений Армянского \\ государственного экономического университета, г. Ереван, Армения
}

\section{А. ПИКА}

д-р экон. наук, профессор, заведуюший кафедрой инновационной экономики, Университет Хоэнхайм, г. Штутгарт, Германия

\section{Аннотация}

B статье рассмотрень вопросы модернизации и инновационного развития экономики Армении. Ситуация стремительно меняется c вступлением Армении в Евразийский экономический союз (ЕАЭС). В новом экономическом пространстве открываются возможности для траектории инновационного роста экономики Республики, открываются новые рынки для расширения экспорта из Армении в страны ЕАЭС.

Но в тоже время усиливается конкурентная борьба внутри союза и только конкурентные товары смогут попасть в новые рынки. В связи с этим Армении нужна грамотная политика в плане организации конкурентного экспорта. Понимая важность быстрых действий в создании конкурентного экспорта в исследовании подробно изучень проблемы технологического развития Армении в изелом. Исследовано международное позиционирование Армении на основе анализа глобального инновационного индекса, которое наглядно показывает на каком технологическом уровне развития находится экономика Республики. Рассмотрень вопросы скорости изменения инновационного развития

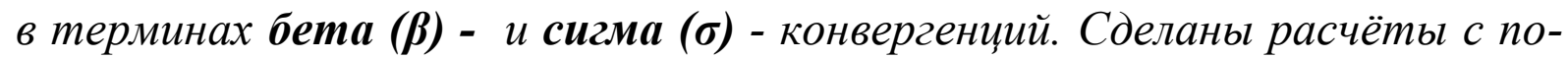
мощьюю эконометрического моделирования, которые помогли понять скорость технологических изменений в трех пространствах (Евразийский экономический союз, Евросоюз и Союз независимых государств - СНГ). Сделань значимые выводы, которые помогут действовать адресно в области обеспечения инновационного развития армянской экономики в новой экономической среде.

Ключевые слова: конвергенция, конкурентоспособность, эконометрические модели, конкурентные преимущества, пространственные данные, скорость трансформации экономики. 


\section{Abstract}

In the article are studied questions linked with modernization and innovative development of economy of Armenia. The situation is changing extensively as Armenia became a member of Eurasian Economic Union. The opportunities for new horizons of the economic growth are being opened in the new economic environment. The markets of republics of union open their doors towards Armenian goods and services.

Meanwhile, the competitive struggle is getting stronger inside Eurasian union economics and only competitive goods can entered into the new areas of the total union market. In this situation Armenia needs in clever and clear policy for organizing competitive export volumes. Knowledge of the importance of rapid actions in creating competitive export forms the issues and challenges of the technological development in Armenian economy which have been examined in details in the article. It is analyzed the global innovation index, which lets us understand the level of Armenian Economy technological development. In the article it is discussed the speed of changes of the innovative development in term of $\beta$ and $\sigma$ convergentions. Econometric models are used to understand the speed of the technological changes in three major areas: Eurasian Economic Union, European Union and CIS which help to find out factors having impact on the real expert of goods and services from Armenia to union republics. In the end of the article important conclusions are existed, they will help targeted act in the field of innovation development of the Armenian economy in the new economic environment.

Keywords: convergention, competitiveness, econometric models, competitive abilites, spatial data, the speed of the transformation of economy.

\section{ВВЕДЕНИЕ}

После распада советского союза сложилась ситуация, при котором страны социалистического блока потеряли давние экономические связи, а для развития новых экономических связей нужна была новая конкурентоспособная экономика. Конечно за 20 лет, например, у Армении, появились многоканальные экономические и культурные отношения с такими высоко развитыми странами мира как Франция, США, Канада на рынках, у которых есть некоторый узкий спектр товаров из Армении. Для расширения ассортимента благ из Армении в западные страны нужны конкурентные товары. С другой стороны, у армянских товаров открыты рынки для стран членов Евразийского экономического союза (ЕАЭС), но тут также ожесточенная борьба, и только конкурентные производители будут в выигрыше. И для Армении, и для стран постсоветского блока важнейшей задачей является преодоление хронической неконкурентности 
отечественного производства. Один из путей - это распространение технологий будущего во все области жизни, во всех странах ЕАЭС, в том числе и в Армении. Важно отметить, что за 20 лет постсоветского развития Армении показало, что для масштабного трансформации экономики или для новой траектории роста нужны огромные финансовые ресурсы и существенный политический вес на политической карте мира. С этой точки зрения участие Армении в разных интеграционных проектах дадут возможность выйти на новые рынки и на ввоз новейших технологий.

\section{РЕЗУЛЬТАТЫ И ИХ ОБСУЖДЕНИЕ}

В данном исследовании были сформулированы три пространства или траектории роста для экономики Армении. Первым приоритетом для разделения этих пространств служит территориальная близость Армении к странам участникам этих пространств. Второе, это тесные экономикокультурные связи, и третье, это разные технологические уровни развития. В работе детально изучено место Армении в этих технологических форматах. Но для того чтобы понять суть технологического развития, надо сперва обозначить общий показатель технологического развития в этих пространствах. В качестве подходящего показателья был подобран показатель глобального инновационного индекса (GII) [1]. Этот индекс рассчитывают в глобальном масштабе с использованием 80 показателей [2]. GII дает наглядное понятие в каком месте находится страна с точки зрения технологического развития в мировом измерении. Так, этот индекс включает два основных понятия (компонента), это:

- Располагаемые ресурсы и условия для проведения инноваций (Innovation Input);

- Достигнутые практические результаты осуществления инноваций (Innovation Output).

Первый компонент объединяет такие показатели, которые оценивают потенциал страны или готовность к инновационным изменениям. Первым фактором показателя проведения инноваций (Innovation Input) являются институты, такие как верховенство закона в исследуемой стране, политическая стабильность, второе, человеческий капитал и исследования, куда входят такие интересные показатели, как расходы страны на учебу, склонность к инновациям, возрастная структура общества, третий показатель - это инфраструктура. Тут внимание обращается к таким показателям, как количество интернет пользователей, персональных компьютеров, инвестиции в телекоммуникационные сектора экономики, четвертое место отведено развитию внутреннего рынка, например доля прямых инвестиций, состояние кредитования, барьеры для выхода 
в национальные рынки и последним показателем является развитие бизнеса, где рассматриваются такие индикаторы, как число компаний инвестирующие в исследования и развитие, технологическая трансформация, состояние использования интернета для бизнес целей.

Второй компонент (Innovation Output) показывает уже достигнутые результаты по адаптации экономики к новым условиям. Так в списке этого компонента намечаются такие показатели, как развитие технологий и экономики знаний и результаты креативной деятельности. Первый показатель включает экспорт высокотехнологичных товаров, инновации в новые технологии, присутствие кластеров в стране. Второй блок показателей включает показатели конкурентоспособности и благосостояние страны. Например, экспорт товаров, экспорт услуг, ВВП на душу населения, индекс потребительских цен ит.д. В данной работе рассмотрены 3 важных вопроса.

- Как страны трех пространств распределены по индексу GII?

- Какая скорость трансформации экономик трех пространств в свете улучшения показателя GII?

- Какие общие проблемы имеют страны с низкой скоростью трансформации экономики?

Для ответа на первый вопрос надо дать четкое обьяснение понятия “трех пространств”. В данной работе страны распределены по трем кластерам, основой формирования которых служат те политические объединения, которые образовались вокруг границ Армении. В таком ракурсе взяты три реальные политико-экономические объединения Европейский союз, СНГ и Евразийский экономический союз. Армения является участником двух последних союзов и тесно сотрудничает с Европейским союзом. Армения связана тесными экономическими и культурными узами с постсоветскими странами, и имеет очень плотные союзнические отношения с Россией. В тоже время многовекторная политика не мешает иметь тесные связи с европейскими странами, например, с Францией. Эти три формата сотрудничества оказывают действенное влияние на формирование индекса GII Армении.

Можно констатировать, что после распада СССР некоторые неолиберальные (“мейнстрым”) концепци стали отправной точкой для перехода от плановой к рыночной экономике всех стран союза и их опыт в некоторых областях дали возможность встать на путь инновационного развитиюя. Надо предпологать, что в обозримом будущем, эти три пространства объединятся, так как это способствует к изменению траектории роста всех экономик уже в едином экономическом, политическом и культурном пространстве. 
Сперва детально познакомимся с динамикой индекса GII Армении [1] в 2011-2015 годах с помощью ниже приведённого графика, рисунок 1.

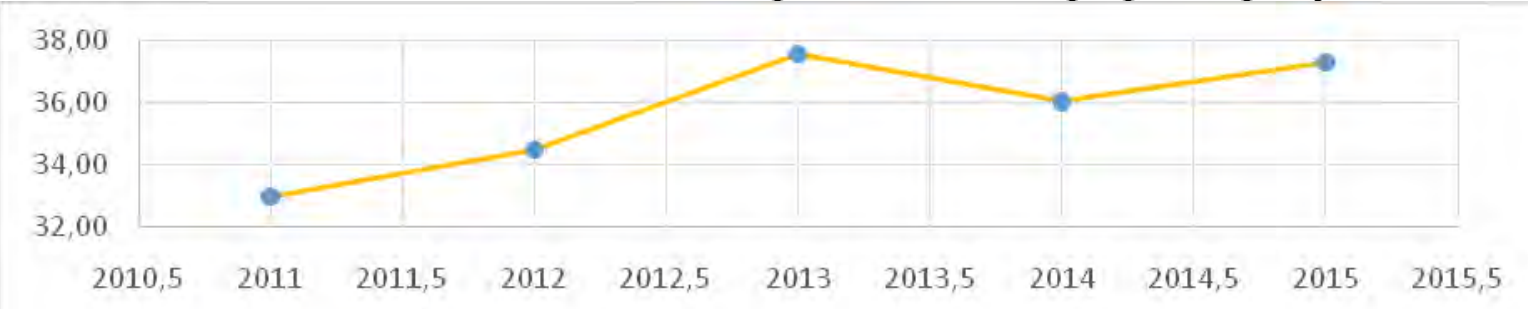

Рисунок 1 - Динамика изменения индекса GII Армении в 20112015 гг. Источник: [1]

Анализируя динамику индекса спомощью графика, можно сказать что в долгосрочной перспективе рост индекса GII очевиден, только в 2014-ом году наблюдался спад индекса. В 2015-ом уже можно видеть рост. Индекс GII в 2015-ом году для Армении составил 37,31. Среднее значение индекса за последние 5 лет составил 30.46. Согласно медодологии максимальное значение индекса 100 (чем ближе к 100, тем лучше). С этой точки зрения Армения показывает не радужные результаты. Но пока рано ставить оценки, так как, надо сравнивать страны выше указанных пространств, с другой стороны, анализировать под категории индекса. Для этого рассмотрим индексы показателей Innovationinput и Innovationoutput в 2011-2015 [1] годах с помощью графиков на рисунке 2.

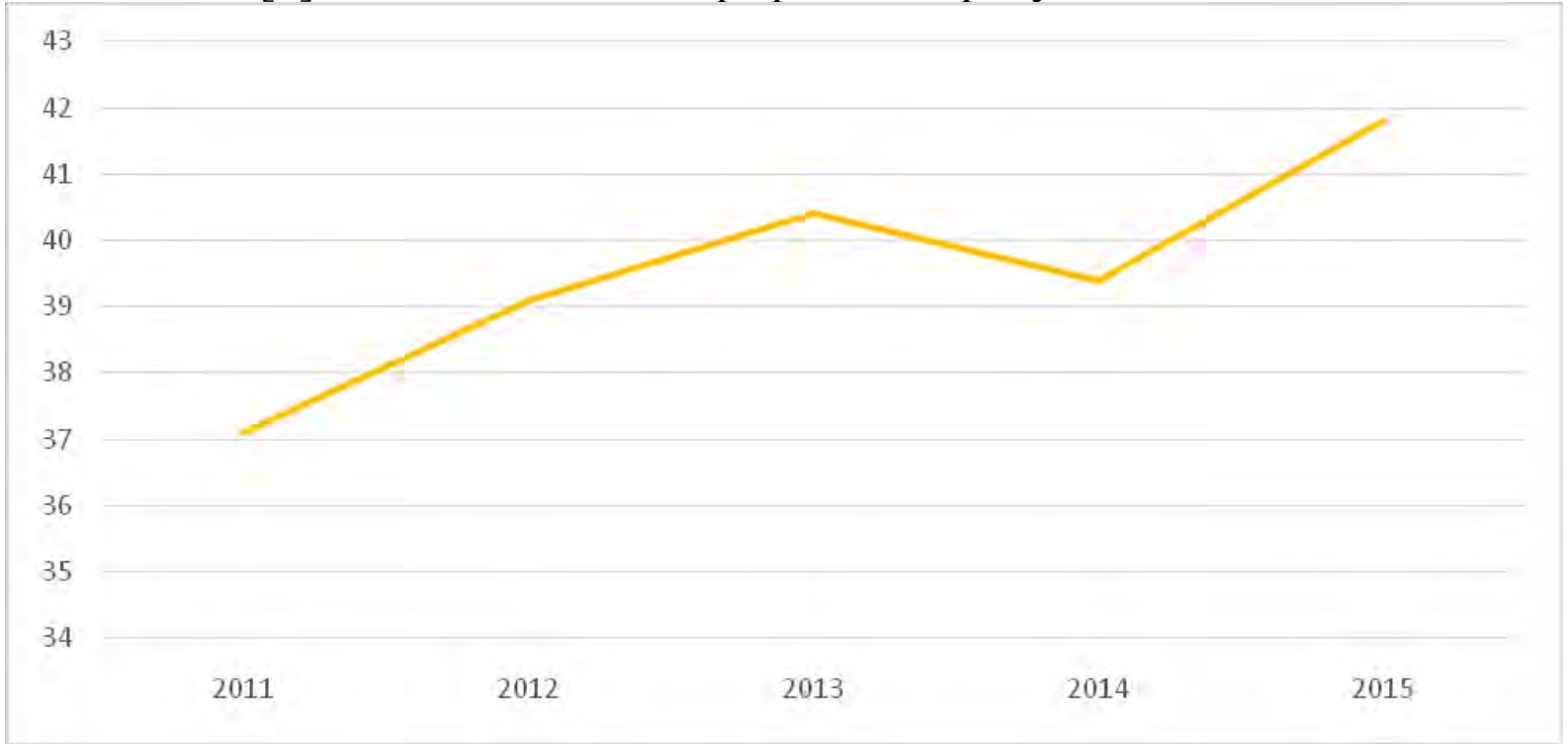

Рисунок 2 - Динамика индекса Innovationinput в 2011-2015 гг. [1]

Индекс располагаемых ресурсов и условия для проведения инноваций или показатель Innovationinput в данном периоде имеет тенденцию роста. Самое большое значение показателя зафиксировано в 2015-ом году - 41,8. Если внутренние предпосылки для инноваций имеют тенденцию роста, 
то другое наблюдается для индекса Innovation Output, которое показывает достигнутые практические результаты осуществления инноваций. Этот показатель занимает свое должное место, так как оценивает эффективность инновационной политики. Наглядно, что динамику Innovation Output в 2011-2015 годах можно отслеживать с помощью графика, приведенного на рисунке 3.

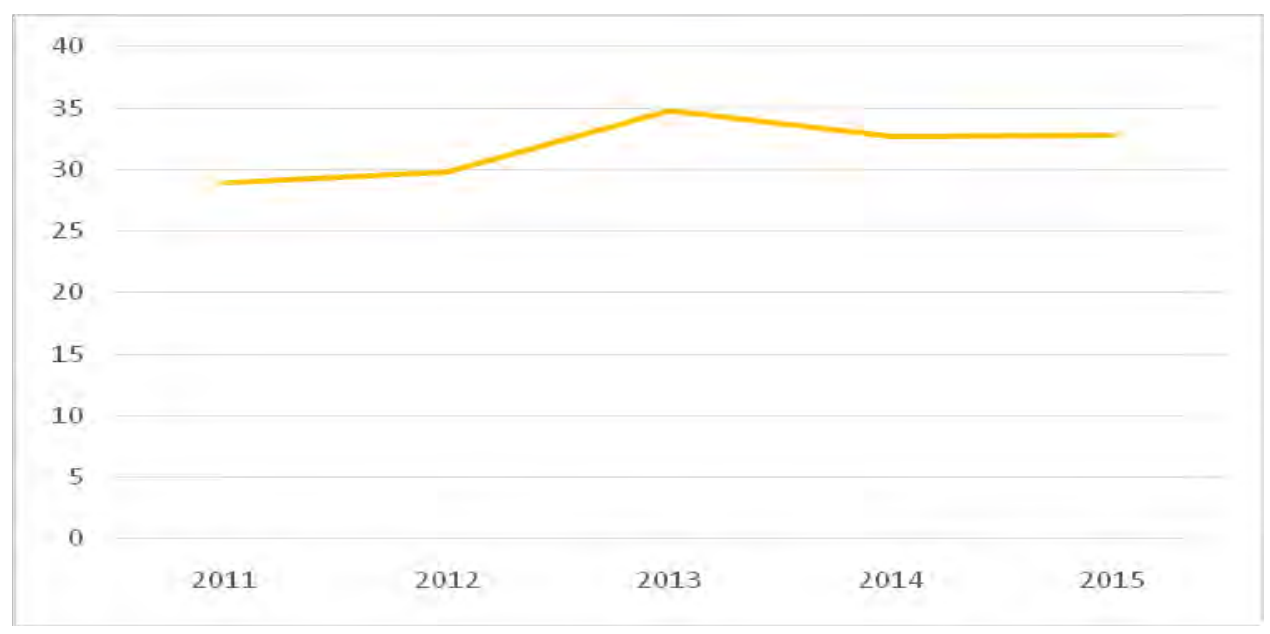

Рисунок 3 - Динамика индекса Innovationoutput в 2011-2015 гг. [1]

Из графика можно сделать вывод, что политика инновационного роста экономики, фактически неудовлетворительны, так как индекс имеет тенденцию снижения, например, в 2013 показатель колебался вокруг значения 34,8 , что слишком плохо, если фактически это значение самое высокое на интервале 2011-2015. Индекс Innovation Output снизился от максимального уровня до 32,8 в 2015 году.

C помощью другого графика, приведенного на рисунке 4, можно фиксировать динамику места Армении в рейтинге стран по показателю GII.

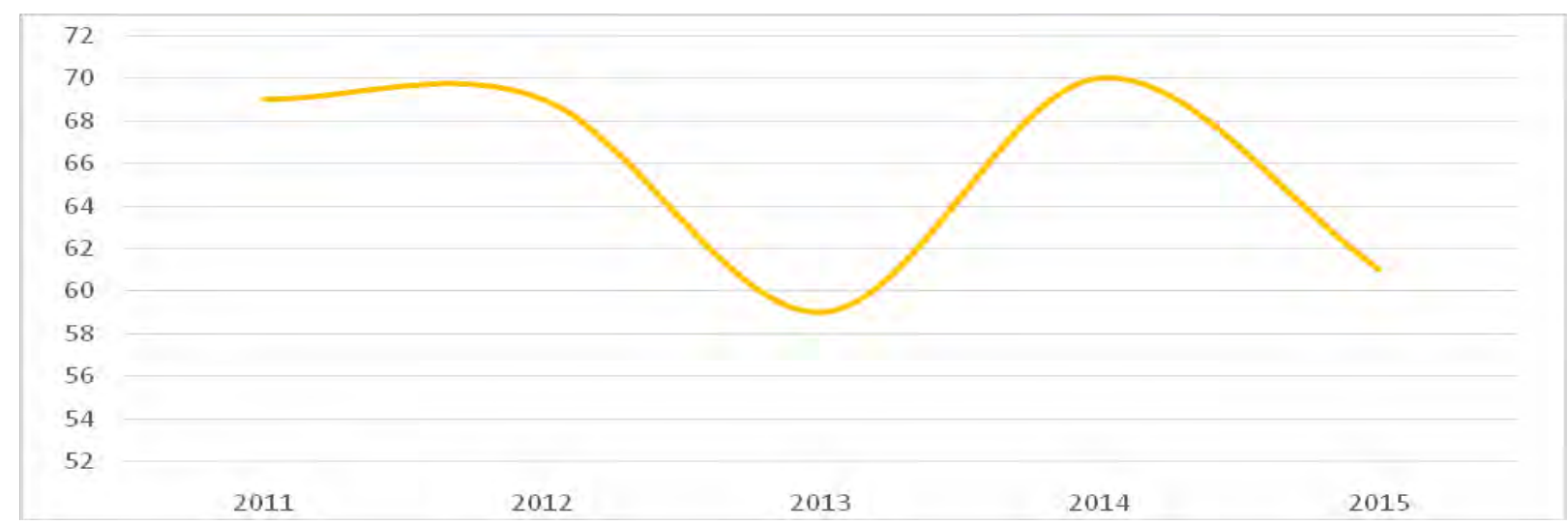

Рисунок 4 - Динамика рейтинга Армении по индексу GII в 20112015 гг. [1] 
Этот показатель показывает, что рейтинг Армении по показателю GII имеет тенденцию снижения. Это хорошо, с точки зрения того, что Армения движется все ближе к кластеру стран с наивысшим уровнем GII, но медленными шагами. Например, в 2015 году Армения поднялась на 61-е место по показателю GII, среди 202 стран. Самое большое изменение рейтинга было зафиксировано в 2013. В этом году наблюдается минимальное значение, равное 59,0.

После детального представления фактов о месте Армении в рейтинге GII можно сравнить показатель GII по странам членом трех крупных объединений на территориях экономико-политических интересов Армении в 2015 году. В сравнительном графике, который приведен на рисунке 5, представлены показатели 37 стран.

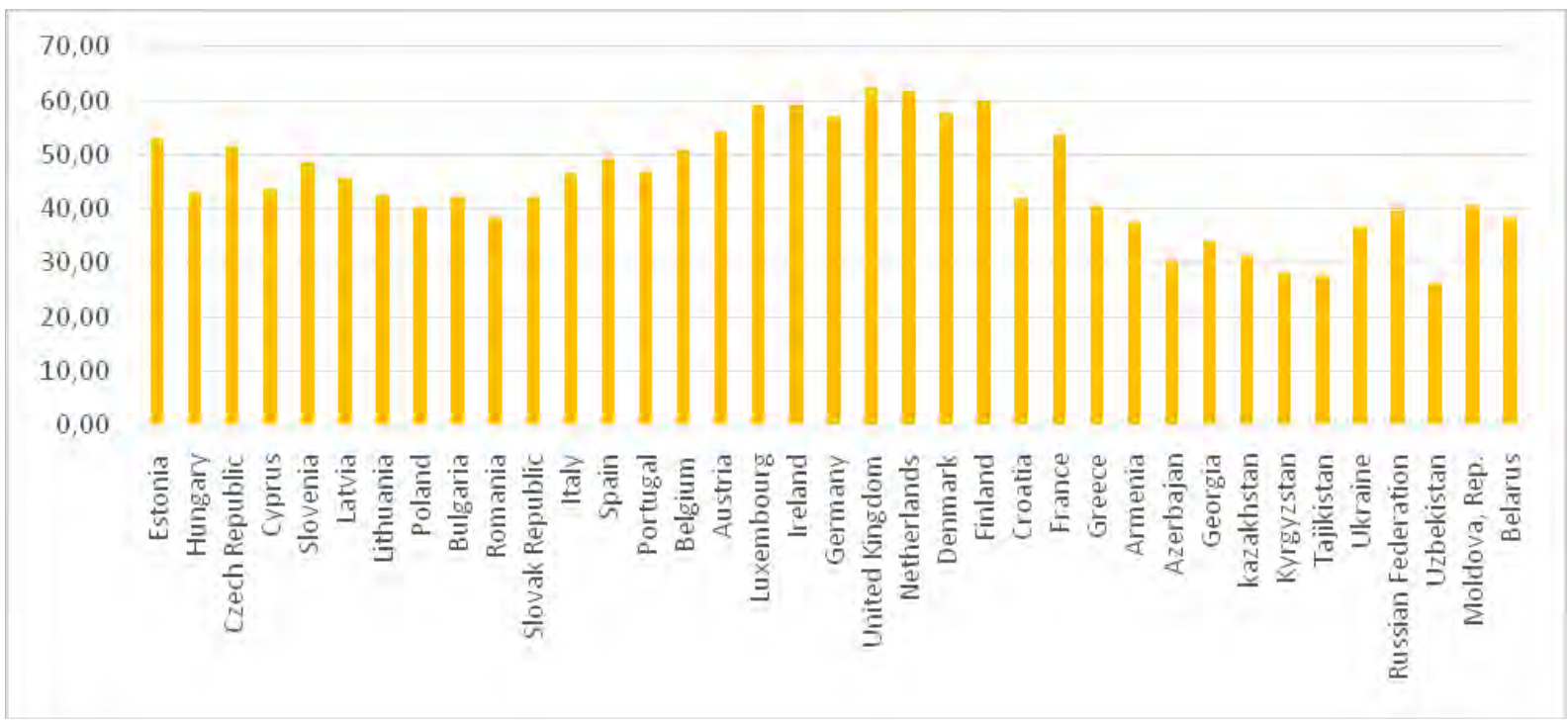

Рисунок 5 - Индекс GII по странам трех пространствв 2015 г.

Из сравнительного графика видно, что абсолютным лидером являются страны Европейского союза - Великобритания и Нидерланды с показателями индекса GII соответственно 62,42 и 61,58. В СНГ абсолютным лидером является Молдавская республика - 40,53. В Евразийском союзе лидер Россия - 39,32, второе место занимает Белоруссия - 38,23, и только третье место занимает Армения -37,31. В Европейском союзе, самый низкий показатель GII у Греции - 34,18. При этом, Греция отстает от Армении на три позиции. Хорошие показатели у новых членов Европейского союза: Эстонии - 52,81, Латвии - 45,51 и Литвы - 42,26. На Южном Кавказе бесспорным лидером по показателю GII является Армения, что является вектором позитивного настроя на инновационность экономики, и с эффективной политикой в этом направлении можно в перспективе надеятся на достижение уровня стран Балтии. 
После детального изучения индекса GII и его составляющих показателей теперь перейдем к рассмотрению вопроса скорости движения к максимальному значению или по крайней мере к лидеру по показателю GII индекса. Стремление стран достичь высоких результатов по индексу GII вполне объективная задача, так как индекс включает очень чувствительные стороны социально-экономической жизни, и особенно по той части, которая связана с институциональными изменениями экономики, что должно привести к новому качеству экономического роста и существенно поднять уровень конкурентоспособности экономики.

При изучении скорости сокращения разницы между странами по индексу GII в работе использованы показатели конвергенции [3]. Бывают разные типы конвергенции: $\boldsymbol{\beta}, \boldsymbol{\sigma}$ и групповая или кластерная конвергенция. Все показатели конвергенции имеют одну общую идею найти скорость изменения разрыва между высокотехнологичными и низкотехнологичными экономиками. Разница между этими типами показателей конвергенции в том, что способы и механизм расчетов у каждого из них разные. Для начала определим начальное и конечное значение индекса GII для стран, входящих в выше определенные три пространства. Наглядно этот процесс можно представить в виде нижеприведенной таблицы, таблица 1.

Таблица 1 - Начальное и конечное значение индекса GII по странам трех пространств

\begin{tabular}{|c|c|c|c|c|}
\hline \multicolumn{5}{|c|}{ Индекс GII по странам участницам трех пространств } \\
\hline $\begin{array}{c}\text { Группы } \\
\text { трех } \\
\text { пространств }\end{array}$ & № & Страна & $\begin{array}{c}\text { Начало периода } \\
-2011\end{array}$ & $\begin{array}{c}\text { Конец } \\
\text { периода - } 2015\end{array}$ \\
\hline 1 & 2 & 3 & 4 & 5 \\
\hline \multirow{5}{*}{ 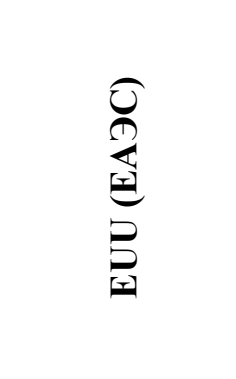 } & 1 & Армения & 33,00 & 37,31 \\
\hline & 2 & Киргизия & 29,79 & 27,96 \\
\hline & 3 & Беларусь & 32,90 & 38,23 \\
\hline & 4 & Российская федерация & 35,85 & 39,32 \\
\hline & 5 & Казахстан & 30,32 & 31,25 \\
\hline
\end{tabular}


Окончание таблицы 1

\begin{tabular}{|c|c|c|c|c|}
\hline 1 & 2 & 3 & 4 & 5 \\
\hline \multirow{26}{*}{ 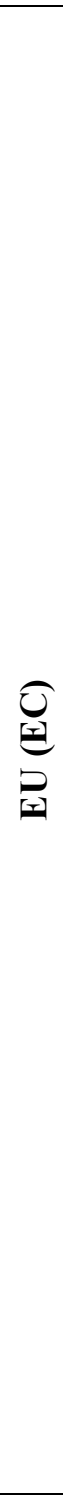 } & 1 & Естония & 49,18 & 52,81 \\
\hline & 2 & Венгрия & 48,12 & 43,00 \\
\hline & 3 & Чехия & 47,30 & 51,32 \\
\hline & 4 & Кипр & 46,45 & 43,51 \\
\hline & 5 & Словения & 45,07 & 48,49 \\
\hline & 6 & Латвия & 39,80 & 45,51 \\
\hline & 7 & Литва & 38,49 & 42,26 \\
\hline & 8 & Польша & 38,02 & 40,16 \\
\hline & 9 & Болгария & 38,42 & 42,16 \\
\hline & 10 & Руминия & 36,83 & 38,20 \\
\hline & 11 & Словакия & 39,05 & 42,09 \\
\hline & 12 & Италия & 40,69 & 46,40 \\
\hline & 13 & Испания & 43,81 & 49,07 \\
\hline & 14 & Португалия & 42,40 & 46,61 \\
\hline & 15 & Белгия & 49,05 & 50,91 \\
\hline & 16 & Австрия & 50,75 & 54,07 \\
\hline & 17 & Люксембург & 52,65 & 59,02 \\
\hline & 18 & Ирландия & 54,10 & 59,13 \\
\hline & 19 & Германия & 54,89 & 57,05 \\
\hline & 20 & Великобритания & 55,96 & 62,42 \\
\hline & 21 & Нидерланды & 56,31 & 61,58 \\
\hline & 22 & Дания & 56,96 & 57,70 \\
\hline & 23 & Финландия & 57,50 & 59,97 \\
\hline & 24 & Хорватия & 37,98 & 41,70 \\
\hline & 25 & Франция & 49,25 & 53,59 \\
\hline & 26 & Греция & 34,18 & 40,28 \\
\hline \multirow{11}{*}{ 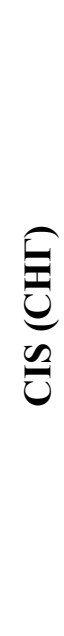 } & 1 & Армения & 33,00 & 37,31 \\
\hline & 2 & Азербайджан & 29,17 & 30,1 \\
\hline & 3 & Грузия & 31,87 & 33,83 \\
\hline & 4 & Казахстан & 30,32 & 31,25 \\
\hline & 5 & Киргизия & 29,79 & 27,96 \\
\hline & 6 & Таджикистан & 24,5 & 27,46 \\
\hline & 7 & Украина & 35,01 & 36,45 \\
\hline & 8 & Российская федерация & 35,85 & 39,32 \\
\hline & 9 & Узбекистан & 23,9 & 25,89 \\
\hline & 10 & Молдова & 38,66 & 40,53 \\
\hline & 11 & Баларусь & 32,9 & 38,23 \\
\hline
\end{tabular}


Как можно увидеть в таблице, анализ ведется в отрезке времени с 2011г. по 2015 г. В первой группе EUU (ЕАЭС) в 2011-ом году самый низкий показатель у Киргизии - 29,79. Характерно, что индекс GII для этой страны имеет тенденцию к снижению, уже в 2015 году значение индекса составило 27,96. В этом плане бесспорным лидером являются Россия и Белоруссия, которые в начале изучаемого периода имели показатели соответственно 35,85 и 32,90 , а в конце периода улучшили свои показатели и в 2015 г. показатели этих стран достигли около 40,00. Третье место занимает Армения, которая тоже улучшила свой показатель GII (сразу на 7,31 пункта). У Казахстана наблюдается самый медленный рост индекса GII, почти на 0,92 пункта.

Теперь анализируем состояние индекса в Европейском союзе. Конечно, по индексу GII страны Европейского союза занимают ведущие позиции не только по сравнению со странами ЕАЭС, но и по таким странам как США, Канада, Япония и другие. Но по отдельным странам ЕС есть существенное ухудшение по линии индекса GII. Так, например, наблюдается спад по двум странам - в Венгрии и в Кипре. В начальном периоде индекс GII показывал значение соответственно 48,12 и 46,45, но в 2015-ом году этот показатель снизился соответственно до уровня 43,00 и 43,51. Надо признать, это существенный шаг назад. Самое низкое значение индекса среди стран ЕС наблюдается в Греции и в начальном и в конечном периоде. Интересная картина наблюдается в новых странах союза. Например, балтийские страны, Польша, Болгария и Румыния показывают хорошие инновационные результаты. Начальное значение индекса GII в этих странах почти одинаковы и колебаются от 36 до 38 . В 2015-ом году по индексу GII первое место среди названный стран занимает Эстония со значением 52,81 , а самый низкий результат у Румынии - 38,20. Надо отметить, что изменение индекса в этом пространстве не так быстротечно, как можно наблюдать у некоторых стран бывшего Советского Союза.

И наконец, проанализируем динамику GII стран Содружества независимых государств. Тут конечно 5 стран из первой группы, другие 6 страны - это постсоветские республики. Интересно то, что 3 государства сейчас остановили членство в СНГ, но долгие годы были членами этой организации, поэтому в нашем анализе они условно включены в третье пространство - пространство СНГ.

Рассмотрим начальные индексы наших близких соседей по Южному Кавказу. Среди этих стран в начальном периоде первое место по значению индекса GII занимала Армения с показателем 33,00, второе место занимала Грузия - 31,87, и последнее место Азербайджан - 29,17. У трех республик намечается прогресс в 2015 году, но изменение позиции по индексу 
не наблюдается и сейчас. Заметно то, что на Южном Кавказе изменение индекса идет медленно только в Азербайджане, его показатель равен 30,1. Если смотреть ситуацию в рамках третьего пространства, то картина такая: самое низкое начальное состояние у Узбекистана и Таджикистана - около 24 пунктов. У этих двух стран наблюдается рост показателя в 2015-ом году, но очень медленный рост - около 2-3 пункта. Падение показателя наблюдается и у Киргизстана (с 29,79 до 27,96). Лидирующие позиции у Молдавской республики $(40,53)$.

С помощью расчета $\boldsymbol{\sigma}$ - конвергенции найдем ответ на второй вопрос данного исследования, которое можно сформулировать так: какая скорость сокращения технологической отсталости в терминах сокращения разницы глобального инновационного индекса среди трех рассматриваемых групп в интервале 2011-2015гг. б - конвергенция показывает темп роста показателя коэффициента вариаций [4]. Результаты расчета увидим в таблице, приведённой ниже.

Таблица $2-\sigma$ - конвергенция по индексу GII в трех пространствах

\begin{tabular}{|c|c|c|c|c|}
\hline \multicolumn{5}{|c|}{ б - конвергенция по индексу GII в трех пространствах } \\
\hline Groups & $\begin{array}{l}\text { Start of period- } \\
2011\end{array}$ & \begin{tabular}{|l|} 
End of period- \\
2015 \\
\end{tabular} & $\begin{array}{l}\text { Change rate or } \\
\sigma \text { convergence } \\
\end{array}$ & $\begin{array}{l}\text { Change rate or } \\
\sigma \text { convergence in } \% \\
\end{array}$ \\
\hline EEU & 0,15 & 0,28 & 0,87 & $87 \%$ \\
\hline $\mathbf{E U}$ & 0,78 & 0,76 & $-0,03$ & $-3 \%$ \\
\hline INU & 0,45 & 0,49 & 0,08 & $8 \%$ \\
\hline
\end{tabular}

Таблица показывает, что разрыв между лидерами и отстающими по индексу GII имеет тенденцию увеличиваться в Евразийском Экономическом Союзе и в Содружестве независимых государств. Так, в евразийском направлении в период 2011-2015 наблюдается отклонения от среднего значения индекса GII на 87\%, в блоке СНГ отклонение на 8\%. В Европейском союзе напротив наблюдается сокращение разрыва между странами с высоким и наименьшим значением индекса GII, так как б конвергенция равна - 3\%.

Следующим этапом рассматривается $\boldsymbol{\beta}$ - конвергенция, но тут сравниваются не группы, а все страны входящие в эти группы. В списке находятся 37 стран, а период анализа остается неизменным. Для нахождения коэффициента $\beta$, используется эконометрическая модель с пространственными данными связывающая логарифм темпа роста с логарифмом начального значения индекса GII. 
Нами сначала была рассмотрена эконометрическая модель [5, с. 67-68], связывающая значения индекса GII с его начальным уровнем в логарифмах.

$$
\ln \mathrm{GII}_{\mathrm{t}}=\alpha_{0}+\beta \ln \mathrm{GII}_{\mathrm{t} 0}+\varepsilon_{\mathrm{t}}
$$

где $\operatorname{lnGII_{t}}$ - значение индекса GII t-ой страны в логарифмах в периоде 2011-2015 гг.,

$\operatorname{lnGII}_{t 0}$ - начальное значение индекса GII t-ой страны в логарифмах в периоде 2011-2015 гг.,

$\alpha_{0}, \beta$-неизвестные параметры модели,

$\varepsilon_{t}-\mathrm{t}$-ое случайная ошибка модели.

Модель была оценена с помощью метода наименьших квадратов [6, стр.13-14]. В результате оценки, все показатели модели были удовлетворительны, кроме значения показателя Дарбина - Ватсона [6, с. 216-224]. Причина такого нарушения, по всей видимости, является ошибка спецификации модели [7]. Для восстановления условий классической модели [8, с. 359-360], нами была добавлена переменная, показывающая лаговое значение объясняющей переменной.

$$
\operatorname{lnGII} t=\alpha_{0}+\beta \operatorname{lnGII} t 0+\alpha_{1} \ln G I I_{t-70}+\varepsilon_{t}
$$

где $\operatorname{lnGII}_{t-70}$ - лаговое значение переменной начального значения индекса GII,

$\alpha_{1}-$ новый неизвестный параметр модели.

В модели (2) рассмотрены вопросы стационарности рядов [5, c. 264-276], переменная lnGII была стационарна в первой разности, для этого рассмотрена модель с первыми разностями.

$$
\mathrm{D}\left(\operatorname{lnGII} \mathrm{t}_{\mathrm{t}}\right)=\alpha_{0}+\beta \mathrm{D}\left(\operatorname{lnGII} \mathrm{t}_{0}\right)+\alpha_{1} \mathrm{D}(\operatorname{lnGII} t-70)+\varepsilon_{\mathrm{t}},
$$

где $D\left(\ln G I_{t}\right), D\left(\ln G I I_{t 0}\right)$ u $D\left(\ln G I I_{t-70}\right)$ - переменные с первыми разностями.

После оценки модели (3) получены такие результаты. 
Таблица 3 - Результаты оценки модели (3)

\begin{tabular}{|c|c|c|c|c|}
\hline \multicolumn{5}{|c|}{ Dependent Variable: $D(\operatorname{LOG}(G I I))$} \\
\hline \multicolumn{5}{|c|}{ Method: Least Squares } \\
\hline \multicolumn{5}{|c|}{ Sample(adjusted): 937} \\
\hline \multicolumn{5}{|c|}{ Included observations: 29 after adjusting endpoints } \\
\hline Variable & Coefficient & Std. Error & t-Statistic & Prob. \\
\hline$D(\operatorname{lnGII0})$ & 0,9 & 0,0558 & 16,16 & 0,0000 \\
\hline$D(\operatorname{lnGIIO}(-7))$ & 0,2 & 0,0843 & 2,34 & 0,0274 \\
\hline $\mathbf{C}$ & 0,006 & 0,0105 & 0,5800 & 0,5669 \\
\hline R-squared & 0,91 & \multicolumn{2}{|c|}{ Mean dependent var } & $-0,0017$ \\
\hline Adjusted R-squared & 0,90 & \multicolumn{2}{|c|}{ S.D. dependent var } & 0,18 \\
\hline S.E. of regression & 0,06 & \multicolumn{2}{|c|}{ Akaike info criterion } & $-2,83$ \\
\hline Sum squared resid & 0,08 & \multicolumn{2}{|c|}{ Schwarz criterion } & $-2,69$ \\
\hline Log likelihood & 44,08 & \multicolumn{2}{|l|}{ F-statistic } & 130,54 \\
\hline Durbin-Watson stat & 1,98 & \multicolumn{2}{|c|}{ Prob(F-statistic) } & 0,0000 \\
\hline
\end{tabular}

Модель (3) имеет высокое качество, все параметры значимы. После некоторых преобразований получена последняя оцененная модель

$$
\widehat{\operatorname{lnGII}}_{\mathrm{t}}=5,43+0,9 \operatorname{lnGII}{ }_{\mathrm{t} 0},
$$

где $\widehat{\operatorname{lnGII}}_{t}$-предсказуемое значение логарифма индекса GII для $t$-ой страны.

Так как модель имеет высокое качество, коэффициент детерминации равен 0,91 [8, с. 107-110], то для нахождения коэффициента конвергенции, можно преобразовать модель следующим образам. Сперва перепишем модель с одним лагом назад, тогда получим

$$
\ln \widehat{\mathrm{GII}}_{\mathrm{t}-1}=5,43+0,9 \operatorname{lnGII} \mathrm{t}-10,
$$

Потом найдем разность уравнений (4) - (5) и разделим обе части нового уравнения на $\ln G I I_{t}$ и получим.

$$
\Delta \widehat{\operatorname{lnGI}}_{\mathrm{t}}=-0,8+0,02 \ln \mathrm{GII}_{\mathrm{t} 0},
$$

где $\Delta \widehat{\operatorname{lnGI} I_{t}}-$ предсказуемое значение темпа роста логарифма индекса GII t-й страны

Из модели (6) видно, что скорость конвергенции равна 0,02 или $2 \%$. 


\section{ВЫВОДЫ}

В исследовании были сформулированы три пространства или траектории роста для Армении. Первым приоритетом для разделения этих пространств служит территориальная близость Армении к странам членам этих пространств. Второе, это тесные экономико - культурные связи, и третье, это разные технологические уровни развития. В работе детально изучено место Армении в этих технологических формированиях.

Полученный результат показывает, что на всем пространстве от Европейского союза до СНГ в период 2011-2015гг. наблюдается снижение темпов движения стран с отстающим индексом GII к лидерам. Причин таких процессов очень много. В общих рамках можно сказать, что свое определенное влияние оказывает общая политическая и экономическая нестабильность: войны на постсоветском пространстве, охлаждение отношений между некогда дружественными странами, проблема беженцев из Сирии, экономические санкции Европейского союза против Российской Федерации.

\section{ЛИТЕРАТУРА}

1. Официальный сайт The global innovation index // электронный pecypc - https://www.globalinnovationindex.org/content/page/GII-Home

2. Официальный сайт Экспертная сеть по вопросам государственного управления [Электронный ресурс] - http://www. gosbook.ru/node/57981

3. Роберт Дж.Барро, Хавьер Сала-и-Мартин, Экономический рост, издательство БИНОМ. Лаборатория знанийй, М: 2010, С. 589-655

4. Официальный сайт Финансовые инвестиции-образовательный центр, информационный портал об инвестициях и инвестиционных инструментах [Электронный ресурс] - http://allfi.biz/financialmanagement/ RiskAnd Returns/kojefficient-variacii.php

5. Я.Р.Магнус, П.К. Катышев, А.А. Пересецкий, Эконометрика, издательство “Дело”, Москва 2004, ст. 67-68

6. Эконометрика:учеб./под ред. И.И.Елисеевой. - М.Юрайт, 2014.

7. Вербик Марно, Путеводитель по современной эконометрике. Пер. с англ. В. А. Банникова. Научн. ред. и предисл. С. А. Айвазяна. - М: Научная книга, 2008. - 616 с. «Библиотека Солев». С. 99-101.

8. Бабешко, Л. О. “Основы эконометрического моделирования”: Учебное пособие. Изд. 2-е, испр. М.: КомКнига, 2006, С. 359-360.

Статья поступила в редакииию 04 октября 2016 года. 